It will be seen that there was a fair degree of correlation betwen the original type of attack and the degree of impairment that followed; that the mild cases more often recorered, and that the severe cases more often were impaired. It would also appear that a higher proportion of attacks with a " positive" bias-using Walshe's classification 1 -were followed by impairment, when compared with those of a " negative" character.

The T'uo Main Types in Cases uith Marked Disablement.

Where the sequelae and degree of disablement were marked two classes could be recognized.

A. The "Restless Naughty Child."-In this class the most constant features are insomnia, nocturnal restlessness, asthenia, pallor, psychic changes, and tics. During the day the child is restless and fidgety, "constantly on the move," as the parents say. He is very often noisy, irritable, nervous and easily frightened, bad tempered, impudent, and lacking in respect.

One boy had on several occasions threatened to commit suicide; in the street he would address strangers with complete familiarity and frequently behaved in a cruel manner to his younger brothers and sisters. As tested by the Binet-Simon scale there was no impairment of intelligence, in fact, there was a tendency to precocity.

In the mental processes of these patients, however, a characteristic impairment is to be found. They cannot maintain concentration on any one subject for any length of time; it is as if the mind, like the body, partook of the general restlessness. At night they are very troublesome; they roll, turn and toss about in bed, stand up and stamp, spit, sing, whistle, shout, clap their hands, and make peculiar noises-grunting, " cheeping," clucking, and blowing. One boy wanted to sharpen something with a knife all night long. This continued to a late hour until exhaustion brought sleep which lasted until late in the following forenoon. In a boy it was reported that on alternate nights the insomnia was absolute, the entire night being spent in restlessness and excitement; in the intervening night he slept heavily for about twelve hours.

In the worst example of this kind, a boy of 6 years, there was a striking degree of precocity combined with very definite evidences of moral degeneration. At one time he contracted a habit of vomiting, and without effort or apparent feeling of sickness he could bring up mouthfuls of undigested food, which he would, if allowed, consume. He would also attempt to embrace everyone who came near. A year after the original infection he was in another hospital, and deterioration was so marked and he was so difficult to deal with that removal to an asylum was being difficult to deal

Nineteen patients, most of whom were between 7 and 14 years of age, fall into this class of the " restless naughty child." The kind of attack which was by far the most productive of these sequelae was the severe choreiform type. Of a total of 35 children dismissed from hospital, 18, or 51 per cent., had developed these changes.

B. The Parkinsonian.-A feature of the-Parkinsonian syndrome is that the same sluggishness which qualifies the thinking and movements of these patients affects also their conative faculties. They have little or no initiative. In the advanced stages they will sit for hours motionless. In less advanced cases it is frequently reported that they will " stay indoors and show no desire to go out." A year after the attack nine patients showed features of the Parkinsonian syndrome to a marked degree, and seven were then in other institutions; in all the condition developed in less than six months after the original attack; in one it appeared immediately after, and in most within one to three months.

In these patients the most common features of the syndrome were muscular rigidity, bradyphrenia, bradykinesia, etc., and salivation. Tremor's were uncommon, only one example being noted-a slow rotatory movement of the head. The muscular rigidity was generalized except in one instance-a boy of 11 years, in whom rigidity with a slight degree of paresis was confined to the right side of the face, the right arm, and right $\mathrm{leg}$. In a woman aged 53 the rigidity was so great that the mouth could not be opened nor the tongue protruded, and considerable effort was required to raise the eyelids. In one young woman with advanced Parkinsonism a disturbance of the respiratory mechanism developed; it was due probably to spasticity of the laryngeal muscles, which has been rarely, if at all, described. Respiration was accomplished by short inspiratory gasps, which were followed by noisy forcible expirations-almost as if she were attempting to blow out a light. The ages of the subjects in this group ranged from 11 to 53 years. Two boys, aged 11, had muscular rigidity, bradyphrenia, bradrkinesia, etc., all to a marked extent. The initial attack in all these cases was severe. In eight patients Parkinsonism had developed only to a slight extent. The most common elements in this group were the trpical facies and some degree of bradyphrenia, bradykiresia, insomnia, and asthenia. Muscular rigidity was, in these patients, confined to the face. The original type of infection, with one exception, was severe.

\section{The S'igns and s'ymptoms.}

The following is a list of the signs and symptoms observed a year after the attack in all patients manifesting sequelae. The total number of cases examined was 128.

\begin{tabular}{|c|c|c|c|c|c|c|}
\hline \multicolumn{2}{|l|}{$\begin{array}{c}\text { Sign or } \\
\text { Syuptom. }\end{array}$} & $\begin{array}{l}\text { No. of } \\
\text { Cases. }\end{array}$ & \multicolumn{2}{|l|}{$\begin{array}{c}\text { Sign or } \\
\text { Symptom. }\end{array}$} & \multicolumn{2}{|c|}{$\begin{array}{l}\text { No. of } \\
\text { Cases. }\end{array}$} \\
\hline Insomnia ... $\quad \ldots$ & & ... 55 & Tics $\quad \ldots \quad \ldots$ & & & \\
\hline Asthenia ... $\quad \ldots$ & $\ldots$ & 46 & Pallor $\quad \ldots$ & $\ldots$ & $\ldots$ & 13 \\
\hline Day drowsiness... & $\ldots$ & 31 & Restlessness & $\ldots$ & $\ldots$ & 11 \\
\hline Psychic changes & $\ldots$ & 24 & Headache & $\ldots$ & $\ldots$ & 11 \\
\hline Nocturnal restles: & & 21 & Pareses ... ... & $\ldots$ & $\ldots$ & 7 \\
\hline Parkinsonism ... & $\ldots$ & 17 & Neurasthenia ... & $\ldots$ & $\ldots$ & 6 \\
\hline Pain $\quad \cdots$ & $\ldots$ & $\ldots$ & Constipation ... & & $\ldots$ & \\
\hline Hyperreflexia & $\ldots$ & $\ldots$ & Adiposity $\quad \ldots$ & $\ldots$ & $\ldots$ & \\
\hline Hyperkinesis $\quad \ldots$ & $\ldots$ & $\ldots$ & Speech changes (ex & xcludi & ing & \\
\hline \multicolumn{3}{|c|}{ Eye symptoms : } & bradyphasia) & & & 6 \\
\hline & & on & Abnormal gait (es & xcludi & ing & \\
\hline Anisocoria $\quad \ldots$ & $\ldots$ & 10 & bradybasia) ... & & & 5 \\
\hline Ptosis $\ldots$ & $\ldots$ & $\ldots$ & Nocturnal enmresis & $\ldots$ & $\ldots$ & \\
\hline Blurred vision & $\ldots$ & $\ldots$ & Absent-mindedness & s... & $\ldots$ & 3 \\
\hline Diplopia $\quad \ldots$ & ... & $\ldots$ & Bulimia ... $\ldots$ & $\ldots$ & & 2 \\
\hline Squint $\ldots$ & $\ldots$ & $\ldots$ & Furunculosis ... & $\ldots$ & $\ldots$ & 2 \\
\hline Myosis ... & ... & & & & & \\
\hline
\end{tabular}

This table affords some conception of the varying range of signs and symptoms that may be presented a year after the attack. The two symptoms which head the list, insomnia and asthenia, were the prominent features in those pationts who were slightly impaired, but still able to follow their occupation, although with more or less difficulty. None of the patients required to be certified mentally deficient.

These notes give some impression of the degree and form of disablement in 128 cases caused within a year by an attack of encephalitis. All degrees of disablement, and many different and complex types, were observed. Disablement-including the slighter forms-existed in $62 \mathrm{per}$ cent., while incapacity to resume work or school was found in 30 per cent.

These figures agree closely with the results of a similar inquiry made in Glasgow. A series of 334 patients who contracted encephalitis lethargica in 1924 was investigated fifteen to eighteen months after the attack, with special reference to the capacity for work. It was reported that 36 per cent. were unfit for work. Some of these -patients had been treated in hospital and some at home.

It has been recognized for some time that the existence of disablement due to encephalitis lethargica constitutes a problem which public health authorities have to face. The problem has been tackled in Scotland, as in other countries, by the establishment of a hospital unit where cases are admitted for special investigation and research.

1 Walshe, F. R. M. : Med. Science, 1920, iii, 51.

\section{HEALED FRACTURES OF TRANSVERSE PROCESSES.}

BY

OWEN L. RHYS, M.D. RADIOLOSIIST, ROYAL INFIRMARY, CARDIFF.

Is 1910, and again in 1913, I published a few cases in the British Medical Journal of what I termed pseudofractures of the lumbar transverse processes. In nearly all there was no history of injury, and I suggested that they were attempts at rib formation. by the costal element in connexion with the transverse processes. Dr. Reginald Morton also emphasized the importance of these conditions from the medico-legal standpoint. 
Since then I have seen scores of cases in which gaps, and wide displacements, appear in several processes, sometimes on both sides of the vertebrae, where no injury had occurred.

In this district, where back injuries and fractured spines are common, the problern of deciding whether trauma has anything to do with the condition shown in a radiograph arises almost every day. In some of the widest separations I have seen, in which perliaps four - processes havo been displaced downwards for an inch or more, there has been no strain or blow, but I have now and then found a similar condition below the seat of an injury, and in several cases the man has placed his finger on a spot as tho seat of pain, which has proved to bo exactly over a separated process. In such cases I always attribute the separation to the injury. The case here illustrated by diagrams

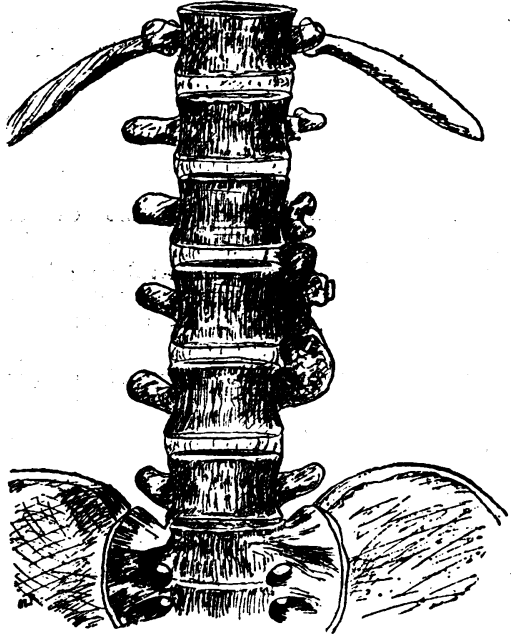

Fia. 1 taken from radiographs is interesting because it for once answers a question which has often been raised-namely, if these processes have been fractured why do they not follow the usual method of healing with callus formation?

A Welsh collier, aged 55, was struck in the left loin by some falling material. He was much bruised and had a small wound. Some weeks later a radiograph showed the first four left lumbar transverse processes separated as shown in the diagram (Fig. 1). The man resumed work, and, after a time, did full collier's work for some months. Then, after an unusual twist, he had pain in the left loin and gave up work. I took the radiograph (Fig. 2) some two and a half years after the first accident. The first process remains as before; the remaining three have fused together in a mass of callus about four inches long and one inch wide, running parallel to but separate from and behind the bodies.
I have previously seen slight attempts at callus formation in single fractured processes, but never anything so extensive as this.

On the rexed question whether strain, as distinct from direct violence, can fracture these processes, I can only say that I have not been satisfied in any case that it has occurred. I think it more likely that muscle or muscle attachment would give before bone. Before I accept even

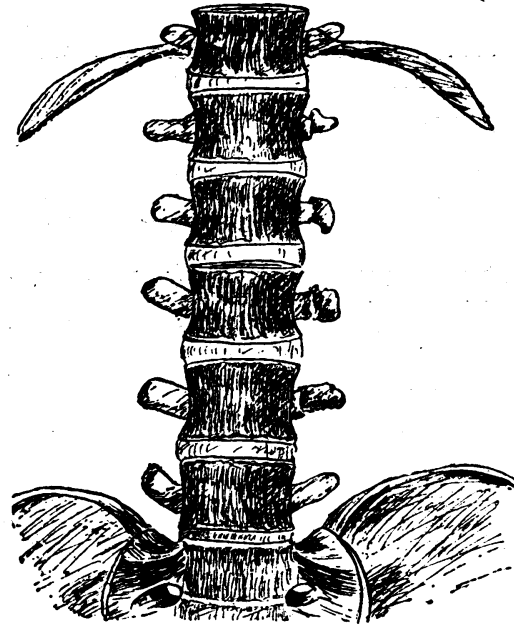

FIG. 8. direct violence as a cause I expect the following conditions to be fulfilled.

1. A definite history of a blow over the site of the suspected fracture. I have seen a workman awarded compensation becausé a radiograph showed a separated second $l \mathrm{u} \mathrm{mbar}$ transverse process. His injury was a fall on the buttocks on a smooth floor, whilst pushing a wheelbarrow. His symptoms were those of sciatica.

2. The lesion must be unilateral. It is inconceivable that an injury could fracture transverse processes on both sides without also fracturing the spinous process.

3 . The immediate after-history should be reasonably consistent with the man having had a severe blow. Considerable force is necessary to break a bone covered as these processes are covered, and I should expect very definite evidence of bruising, and probably a wound. So much depends upon the man, that his capacity for working on varies enormously. Some of the old Welsh colliers have extraordinary powers of bearing pain, and will manage to walk home after such an injury, but any attempts at working or stooping would naturally be extremely painful.

\section{AN INFLUENZAL CONDITION SIMULATING THE ACUTE ABDOMEN. \\ BY}

\section{R. St. LEGER BROCKMAN, M.ChIR., F.R.C.S.,}

ASSISTANT SURGRON TO THE SHEFFIELD ROYAL INFIRMARY.

THE responsibility of deciding whether a case is one needing the immediate aid of surgery, or whether the abdominal signs are the mask of a medical condition, is no uncommon experience. When faced with this type of case the medical practitioner will be alive to the possibility of pneumonia or of a sudden pneumothorax, of uraemia, and of the nervous crises of tabes and pernicious anaemia; but when all these have been reckoned with there remains another class not infrequently submitted to needless surgery.

Many can call to mind a case in which the abdomen was opened under the impression that an acute catastrophe had taken place, but no gross lesion of any organ could be discovered, only a slight amount of free fluid, sometimes blood-stained, scattered petechial haemorrhages, and small bags of jelly-like lymph. After careful search a more or less normal appendix has been removed, and the surgeon has closed the abdomen with no small degree of secret chagrin.

During the last two years I have seen in consultation a series of fifteen cases, all remarkably constant in general type, with marked signs and symptoms pointing apparently to some acute surgical intra-abdominal lesion. In one instance I performed laparotomy on the diagnosis of acute intestinal obstruction. I found the free fluid, the jelly-like lymph, and the subperitoneal petechiae. There was in addition, in the lower portion of the ileum, a persistent contraction ring with distended gut above and collapsed intestine below. No organic cause of any nature could be discovered. This man recovered in spite of the treatment, whilst all the others have reached the same happy ending without the intervention of surgery.

These cases form, I believe, a definite clinical condition, which can mimic, as it did in this series, any type of acute surgical abdominal condition. Taking this case which I opened with the previous sporadic ones exhibiting similar intra-abdominal findings, and comparing all as regards their clinical signs and symptoms, I think that it is possible to offer a reasonable hypothesis for their cause and pathology.

The onset was sudden; vomiting of bile-stained material was an early sign, but was not persistent. The patient was seized with the most acute pain without any previous feeling of malaise or other warning symptom. In somic the pain was in the upper abdomen, in others in the lower. The acute spasms of pain were intermittent, with intervals of comparative freedom varying from five to fifteen minutes. During the spasm the muscles in the affected area could be felt, and at times could be seen to go into a condition of cramp. During the attack there was board-like rigidity in the affected area which did not completely disappear with the pain. Palpation caused pain, but the pationt complained beforo the pressure of the examining hand had reached the peritoneum. The tender layer appeared to lio in the muscles of the abdominal wall rather than in the peritoneum. It is a distinction which is not very easy to explain in writing, but it can be clearly observed in the clinical examination.

The severity of the pain was most marked, and the way in which it could wring a cry from strong men suggested, when seen for the first time, that an acute perforation of 